\title{
Comparative Study between Dermo, Pelite, and Seal-In X5 Liners: Effect on Patient's Satisfaction and Perceived Problems
}

\author{
Sadeeq Ali, Noor Azuan Abu Osman, Nooranida Arifin, Hossein Gholizadeh, \\ Nasrul Anwar Abd Razak, and Wan Abu Bakar Wan Abas \\ Department of Biomedical Engineering, Faculty of Engineering, University of Malaya, 50603 Kuala Lumpur, Malaysia \\ Correspondence should be addressed to Sadeeq Ali; sadeeqcpo@yahoo.com
}

Received 10 June 2014; Revised 18 July 2014; Accepted 21 July 2014; Published 11 August 2014

Academic Editor: Ali Hosseini

Copyright (C) 2014 Sadeeq Ali et al. This is an open access article distributed under the Creative Commons Attribution License, which permits unrestricted use, distribution, and reproduction in any medium, provided the original work is properly cited.

Purpose. This study aimed to compare the effect of satisfaction and perceived problems between Pelite, Dermo with shuttle lock, and Seal-In X5 liners on the transtibial amputees. Material and Methods. A total of thirty transtibial amputees (17 male, 13 female) volunteered to take part in this research. Two prostheses were fabricated for each participant. Prosthetic Evaluation Questionnaire (PEQ) was filled in by the participants with the three liners. Results. The statistics highlight that Dermo liner showed significantly higher score $(P=0.05)$ in walking, walking on uneven surfaces, stairs walking, fitting, donning/doffing, sitting, suspension, and overall satisfaction with Dermo liner compared with Seal-In X5 and Pelite liners. Overall satisfaction was 34\% higher with Dermo liner than Seal-In X5 liner and 28\% higher than Pelite liner. Participants reported less problems with Dermo liner and significant differences $(P<0.05)$ were recorded between the three liners in sweating, skin irritation, frustration, and pain compared with SealIn X5 and Pelite liners. Conclusion. Participants experienced high level of satisfaction and practiced fewer problems with Dermo liner. These results showed that there is good indication to believe that Dermo liner might be a good choice for transtibial users and might help the clinicians and prosthetic practitioners in selection criteria of prosthetic liners.

\section{Introduction}

Manufacturing of devices suited to individuals is a key element to recover physical capabilities. One such device is prosthesis which is aimed to substitute the loss of a limb which has lost its cosmetic and desirability for the amputee. Lower limb prosthesis can be composed of several components such as the socket, liner, shank, ankle, and foot. Among these components socket and liner are the important parts of the prosthesis due to its interface among the residuum and socket [1-3]. Poor socket fitting due to enhanced pressure between socket and residuum greatly reduces the activity level of prosthetic users $[4,5]$. Amputees hold high ambulatory loading during using the prostheses in their daily activities, which is usually transferred to skeletal structure from the prosthesis via interface among residuum and prosthetic socket [6-8]. Residuum tissues are not accustomed to shear loading and skin pressure during activities. Amputee's skin is vulnerable to develop cyst, edema, dermatitis, and blisters; it is not uncommon to experience residuum skin problems in lower limb amputees $[9,10]$, which effect the performance and comfort of the amputee [11].

Prosthetic users required a comfortable liner and good socket to avoid skin problems and to prevent discomfort while using the prosthesis for daily activities [12,13]. Cushioning effect of the liners lessens peak pressure and shear forces between the socket and residuum to prevent skin breakdown [14]. To make the prosthetic socket more comfortable prosthetic liners are frequently prescribed for lower limb amputees [15]. A numbers of liners are available in the market for transtibial amputees. Clinicians have been using Pelite foam liner since 1950 [16-18]. Pelite is a type of expanded crosslinked sponge foam which is shaped to fit to residuum to provide cushioning inside the socket. Many types of strategies are used to achieve a variety of suspension with Pelite liner, including suprapatellar strap or cuff or supracondylar bulge or suspension sleeve worn over the socket and extending to mid-thigh [17].

Lately, liners with superior quality have been introduced in the market. Manufacturers claim that the new liners are 


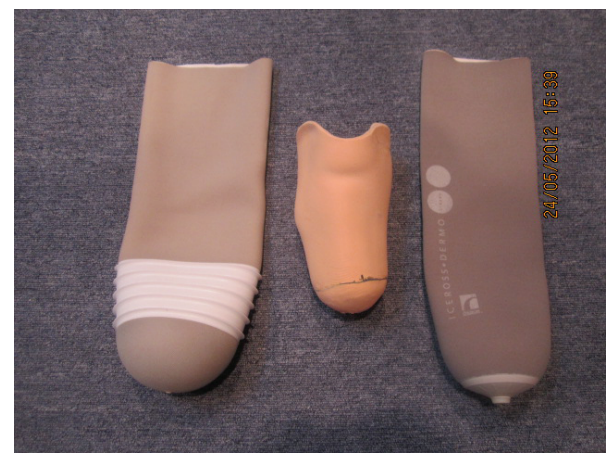

FIGURE 1

more comfortable with better suspension and provide relief of dermatological problems compared with previous prosthetic designs $[9,19,20]$. A wide range of liners with various properties are offered today, including the recent offering of Iceross Dermo and Seal-In X5 liners (Figure 1). Both the liners are composed of silicon material but the suspension mechanism is different. Dermo liner suspension is based on shuttle lock system, while Seal-In X5 liner has five seals around the liner for suspension conforming to the residuum shape and socket inner wall, establishing an air tight seal. Silicon liners are rolled on the patient's residuum, which enhance the contact surface with socket and provide a comfortable cushion between the prosthetic socket and residuum.

Researchers have developed many prosthetics/orthotics questionnaires to evaluate patients' satisfaction with prostheses and orthoses [20-26]. Prosthetics Evaluation Questionnaire (PEQ) is the most common type of questionnaire and majority of the researchers have mostly used PEQ to evaluate differences in performance, function, and satisfaction among different prosthetics technique or components $[22,26]$. The PEQ is grouped into nine validated scales which consist of eighty-two items, and there are a number of one hundred and eleven additional individual questions pertaining to pain, satisfaction, transfer, self-efficacy, and prosthetic care. All the scales of PEQ have been validated for test-retest and internal consistency [22]. The PEQ scales are not dependent on each other, so it is reasonable to use only the scales that are pertinent to your research question. Visual analog scale format is used for PEQ questions and each line is $100 \mathrm{~mm}$ long and is always measured from the left (0-100) [22].

Many studies have been carried out to check the level of satisfaction and problems with transtibial liners but most of the studies are just a questionnaires survey or interview based study without fabricating prostheses for participants [27-29]. However, there is no comparative study in the literature regarding the satisfaction and perceived problems among the Pelite, Seal-In X5, and Dermo liners. Therefore this study aimed to compare the effect of satisfaction and perceived problems among Pelite, Dermo liner with pin/lock, and SealIn X5 liner on the transtibial amputees.

\section{Materials and Methods}

2.1. Participants. Thirty transtibial amputees ( 17 male, $13 \mathrm{fem}-$ ale) volunteered to take part in this research. All the partici-
TABLE 1: Characteristics of the participants.

\begin{tabular}{lc}
\hline Age: years, mean (SD) & $46.02 \pm 15.10$ \\
Sex: $n(\%)$ & $17(56.6 \%)$ \\
Male & $13(43.33 \%)$ \\
Female & $75.73 \pm 14.03$ \\
Weight: kg, mean (SD) & $170.14 \pm 6.70$ \\
Height: cm, mean (SD) & \\
Education; $n$ (\%) & $6(20 \%)$ \\
High school & $8(26.66 \%)$ \\
Diploma & $9(30 \%)$ \\
Degree & $7(23.33 \%)$ \\
P. Graduate & $7.57 \pm 3.56$ \\
Years since amputation: mean (SD) & \\
Reason for amputation: $n$ (\%) & $12(40 \%)$ \\
Diabetic & $9(30 \%)$ \\
Trauma & $5(16.66 \%)$ \\
PVD & $4(13.33 \%)$ \\
Other & \\
Amputation side & $12(40 \%)$ \\
Right & $18(60 \%)$ \\
Left & \\
Activity level: $n$ (\%) & $7(23.33 \%)$ \\
K2 & $6(20 \%)$ \\
K3 & $7(23.33 \%)$ \\
K4 & $9.23 \pm 2.90$ \\
\hline Prosthetics use every day: hours (SD) &
\end{tabular}

PVD: peripheral vascular disease.

pants had a unilateral amputation minimum 3 years prior to this study, who were using PTB and KBM sockets prosthesis with Pelite liner, single axis foot, and solid ankle cushioned heel $(\mathrm{SACH})$ foot. The detailed particulars are shown in Table 1. University Malaya Medical Centre ethics committee approved this study, and the participants gave his/her written consent.

2.2. Prosthetic Intervention. A total of sixty transtibial prostheses were made up with Seal-In X5 liner with Icelock Expulsion Valve 551, Dermo liner with Icelock-200 series, socket adaptor, pylon tube, male pyramid adapter, female pyramid adapter, double adapter, and SACH foot. We fabricated two prostheses for each participant, one TSB with Dermo liner and the other TSB socket with Seal-In X5 liner. First we fabricated the prostheses with Dermo liner. Dermo liner was applied to the participant residuum properly and cellophane was applied on the liner to protect it. All the measurements and boney prominent regions were marked with transparent marker and the residuum measurements were documented. Plaster of Paris (POP) bandages were applied to residuum and massaged properly. Once the cast dried, it was removed from the participant residuum. All the marks were refreshed and negative cast was filled with POP powder. Recommended reduction was done from the positive model after removing the negative cast. Positive model was properly clean and lock was attached to the distal part of the model. Transparent 
plastic molding was done to get a clear socket. Clear socket was smoothed and attached with the other components. Same procedure was repeated for Seal-In X5 liner socket except that expulsion Valve was used instead of lock.

In PTB socket participants were using supracondylar suspension system and suprapatellar strap, while in TSB socket the suspension was provided through Pin/lock with Dermo liner and vacuum suspension with Seal-In X5 liner. Participant walked with the two new prostheses under the supervision of the certified prosthetist to become familiar with them. Once the participants were satisfied with the fitting, his/her next step was to use each prosthesis for at least 60 days. Participants were requested to come to the brace and limb laboratory once a week for prostheses reviews and if they required adjustment.

2.3. Questionnaire. In order to study the effect of the three different prosthetic liners on participant's satisfaction and to identify their problems with the use of the prosthesis, we used some elements of the PEQ. The questionnaire consists of demographic variables (sex, age, education level, marital status, height, and weight), amputation side, cause of amputation, and years since amputation. In addition, we asked some questions related to the activity levels of the participants. Four activity levels were as follows: household ambulator (K1), limited community ambulator (K2), community ambulator (K3), and high level user (K4). Medicare Functional Classification Level (MFCL) defined these levels of activities [30]. The questionnaire also included questions about participant's satisfaction and asked for details of any prosthetic-related problems that the participant experienced with each liner. In the satisfaction section of the questionnaire, participants were asked about the walking ability of the prosthesis, prosthetic fit, ability to walk up and down stairs, donning and doffing ability with their prostheses, uneven surfaces walking ability, prosthesis appearance, sitting ability with prosthesis, feeling with prosthesis, weight of the prosthesis, and overall satisfaction. Problems with the prosthesis consisted of sweating, skin irritation, wounds, pain, swelling, bad smell of residuum or prosthesis, sounds, and frustration with the prosthesis. A scale $0-100$ was used to score overall satisfaction with the prosthesis, with 0 indicating that a participant was "unsatisfied" with his/her liner and 100 being indicative of "completely satisfied." We used the same $0-100$ scale of measurement for problems related variables, where 0 indicated "extremely bothered" and 100 indicated "not at all bothered."

2.4. Data Collection. To avoid any mistake we explained all the questions of the questionnaire one by one to all the participants and teach them how to record your satisfaction or problems score with each prosthesis. Three separate PEQs were completed from each participant with the three different prostheses. As all the participants were using Pelite liner before the study prostheses, therefore questionnaire with Pelite liner was completed on first visit of each prosthesis before the casting for TSB sockets. After the 60-day trial period with each study prosthesis, the participants came to laboratory to complete the questionnaires for Dermo and
Seal-In X5 liners prostheses to score and share his/her experience about the liners.

2.5. Statistical Analysis. We used nonparametric statistical analysis for data to evaluate the differences between the three liners on four main regions (anterior, posterior, medial, and lateral) and subregions (proximal and distal) of each main region. Therefore we used Kruskal-Wallis test to compare the satisfaction and perceived problems between the three liners. Analysis was performed by using version 21 of SPSS (SPSS Inc., Chicago, IL, USA) and level of significance was set at $P<$ 0.05 for all analyses.

\section{Results}

The finding highlights that participants were more satisfied with Dermo liner and showed significantly higher score $(P=$ 0.05 ) compared with Pelite and Seal-In X5 liners (see Table 2). No differences were recorded with the three liners in sitting with prosthesis, appearance of prosthesis, and weight of the prosthesis (see Table 2). Donning and doffing was significantly challenging $(P=0.00)$ with Seal-In X5 liner compared with Pelite and Dermo liners (59.00 versus 87.00 and 92.00 , resp.). Overall satisfaction score was mean $=85.00, \mathrm{SD}=$ 2.5 with Dermo and means $=63.00, \mathrm{SD}=7.91$ with Seal-In $\mathrm{X} 5$ liner and mean $=66.00, \mathrm{SD}=11.25$ with Pelite liner (see Table 2).

Participants experienced less sweating with Pelite liner compared with Dermo and Seal-In X5 liners (mean $=92, \mathrm{SD}=$ 5.37 versus mean $=76, \mathrm{SD}=5.1$ versus mean $=67, \mathrm{SD}=2.58$, $P<0.01$, resp.). More frustration, pain, and skin irritation were recorded with the Seal-In X5 and Pelite liners (see Table 2). No significant difference was observed in swelling, wound, smell, and sound with the three liners (see Table 2).

3.1. Comparison between Dermo and Seal-In X5 Liners. Participants showed significant $(P<0.05)$ differences between Dermo and Seal-In X5 liners in seven questions out of ten. Participants experienced $43.71 \%$ higher satisfaction during donning and doffing and $43.82 \%$ during level walking with Dermo liner compared with Seal-In X5 liners. Satisfaction was $50.34 \%$ more during feeling with the prosthesis and $29.45 \%$ higher during walking on uneven surfaces with the Dermo liner compared with Seal-In X5 liners. Overall, participants were $29.72 \%$ more satisfied with Dermo liner compared with Seal-In X5 liner. Participants noticed significantly less problems with regard to sweating (76.00 versus 67.00 , $P=0.00$ ), skin irritation (90 versus $83, P=0.00$ ), pain $(99.00$ versus $80.00, P=0.00$ ), and frustration ( 90.00 versus 71.00 , $P=0.00$ ) with Dermo liner compared with Seal-In X5 liner, respectively (see Table 3 ).

3.2. Comparison between Dermo and Pelite Liner. Participants were more satisfied with Dermo liner compared with Pelite liner and demonstrated significant $(P<0.05)$ differences during fit of the prosthesis ( 87.00 versus $74.00 ; P=0.00$, resp.), donning/doffing (92.00 versus $87.00 ; P=0.05$, resp.), sitting with the prosthesis $(90.00$ versus $83.00 ; P=0.03$, 
TABLE 2: Comparison between the three liners.

\begin{tabular}{|c|c|c|c|c|}
\hline Variable & Dermo & Seal-In X5 & Pelite & $P$ value \\
\hline & \multicolumn{4}{|c|}{ Satisfaction } \\
\hline Fit of prosthesis & $87.00(2.53)$ & $78.00(2.73)$ & $74.00(4.10)$ & 0.00 \\
\hline Donning/doffing & $92.00(2.63)$ & $59.00(12.41)$ & $87.00(8.12)$ & 0.00 \\
\hline Sitting with prosthesis & $90.00(6.70)$ & $87.00(4.27)$ & $83.00(6.32)$ & 0.06 \\
\hline Walking with prosthesis & $89.00(5.17)$ & $57.00(12.70)$ & $78.00(5.37)$ & 0.00 \\
\hline Walking on uneven surface & $74.00(5.70)$ & $55.00(8.35)$ & $66.50(4.74)$ & 0.00 \\
\hline Walking on stairs & $67.00(5.35)$ & $62.00(7.17)$ & $62.50(5.40)$ & 0.01 \\
\hline Appearance of prosthesis & $87.00(2.73)$ & $87.00(2.73)$ & $85.00(4.71)$ & 0.51 \\
\hline Feeling with prosthesis & $92.00(2.73)$ & $55.00(11.24)$ & $69.00(7.10)$ & 0.00 \\
\hline Weight of prosthesis & $86.00(5.47)$ & $86.00(5.47)$ & $86.00(5.16)$ & 1.00 \\
\hline Suspension & $88.50(7.07)$ & $91.00(7.37)$ & 74.50 (11.41) & 0.00 \\
\hline \multirow[t]{2}{*}{ Overall satisfaction } & $85.00(2.5)$ & $63.00(7.91)$ & $66.00(11.25)$ & 0.00 \\
\hline & \multicolumn{4}{|c|}{ Problems } \\
\hline Sweating & $76.00(5.1)$ & $67.00(2.58)$ & $92.00(5.37)$ & 0.00 \\
\hline Sound & $80.00(6.66)$ & $82.00(8.10)$ & $80.00(6.66)$ & 0.74 \\
\hline Skin irritation & $90.00(0.00)$ & $83.00(5.41)$ & $75.00(7.45)$ & 0.00 \\
\hline Smell & $78.00(8.11)$ & $78.00(7.91)$ & $75.00(8.81)$ & 0.69 \\
\hline Wound & $92.00(8.10)$ & $90.00(9.42)$ & $85.00(9.42)$ & 0.19 \\
\hline Pain & $99.00(2.10)$ & $80.00(3.33)$ & $70.00(5.77)$ & 0.00 \\
\hline Frustration & $90.00(3.33)$ & $71.00(7.10)$ & $71.00(6.14)$ & 0.00 \\
\hline Swelling & $88.00(2.60)$ & $88.00(4.21)$ & $85.00(4.71)$ & 0.18 \\
\hline
\end{tabular}

Satisfaction: 100 represented "completely satisfied" and 0 indicated "not satisfied at all."

Problem: 100 represented "not bothered at all" and 0 indicated "extremely bothered."

TABle 3: Comparison between Dermo and Seal-In X5 liners.

\begin{tabular}{|c|c|c|c|}
\hline Variable & Dermo & Seal-In X5 & $P$ value \\
\hline & \multicolumn{3}{|c|}{ Satisfaction } \\
\hline Fit of prosthesis & $87.00(2.53)$ & $78.00(2.73)$ & 0.00 \\
\hline Donning/doffing & $92.00(2.63)$ & $59.00(12.41)$ & 0.00 \\
\hline Sitting with prosthesis & $90.00(6.70)$ & $87.00(4.27)$ & 0.23 \\
\hline Walking with prosthesis & $89.00(5.17)$ & $57.00(12.70)$ & 0.00 \\
\hline Walking on uneven surface & $74.00(5.70)$ & $55.00(8.35)$ & 0.00 \\
\hline Walking on stairs & $67.00(5.35)$ & $62.00(7.17)$ & 0.03 \\
\hline Appearance of prosthesis & $87.00(2.73)$ & $87.00(2.73)$ & 1.00 \\
\hline Feeling with prosthesis & $92.00(2.73)$ & $55.00(11.24)$ & 0.00 \\
\hline Weight of prosthesis & $86.00(5.47)$ & $86.00(5.47)$ & 1.00 \\
\hline Suspension & $88.50(7.07)$ & $91.00(7.37)$ & 0.46 \\
\hline \multirow[t]{2}{*}{ Overall satisfaction } & $85.00(2.5)$ & $63.00(7.91)$ & 0.00 \\
\hline & \multicolumn{3}{|c|}{ Problems } \\
\hline Sweating & $76.00(5.1)$ & $67.00(2.58)$ & 0.00 \\
\hline Sound & $80.00(6.66)$ & $82.00(8.10)$ & 0.51 \\
\hline Skin irritation & $90.00(0.00)$ & $83.00(5.41)$ & 0.00 \\
\hline Smell & $78.00(8.11)$ & $78.00(7.91)$ & 0.87 \\
\hline Wound & $92.00(8.10)$ & $90.00(9.42)$ & 0.63 \\
\hline Pain & $99.00(2.10)$ & $80.00(3.33)$ & 0.00 \\
\hline Frustration & $90.00(3.33)$ & $71.00(7.10)$ & 0.00 \\
\hline Swelling & $88.00(2.60)$ & $88.00(4.21)$ & 0.57 \\
\hline
\end{tabular}

Satisfaction: 100 represented "completely satisfied" and 0 indicated "not satisfied at all."

Problem: 100 represented "not bothered at all" and 0 indicated "extremely bothered." 
TABle 4: Comparison between Dermo and Pelite liner.

\begin{tabular}{|c|c|c|c|}
\hline Variable & Dermo & Pelite & $P$ value \\
\hline & \multicolumn{3}{|c|}{ Satisfaction } \\
\hline Fit of prosthesis & $87.00(2.53)$ & $74.00(4.10)$ & 0.00 \\
\hline Donning/doffing & $92.00(2.63)$ & $87.00(8.12)$ & 0.05 \\
\hline Sitting with prosthesis & $90.00(6.70)$ & $83.00(6.32)$ & 0.03 \\
\hline Walking with prosthesis & $89.00(5.17)$ & $78.00(5.37)$ & 0.00 \\
\hline Walking on uneven surface & $74.00(5.70)$ & $66.50(4.74)$ & 0.00 \\
\hline Walking on stairs & $67.00(5.35)$ & $62.50(5.40)$ & 0.00 \\
\hline Appearance of prosthesis & $87.00(2.73)$ & $85.00(4.71)$ & 0.33 \\
\hline Feeling with prosthesis & $92.00(2.73)$ & $69.00(7.10)$ & 0.00 \\
\hline Weight of prosthesis & $86.00(5.47)$ & $86.00(5.16)$ & 1.00 \\
\hline Suspension & $88.50(7.07)$ & $74.50(11.41)$ & 0.01 \\
\hline \multirow[t]{2}{*}{ Overall satisfaction } & $85.00(2.5)$ & $66.00(11.25)$ & 0.00 \\
\hline & \multicolumn{3}{|c|}{ Problems } \\
\hline Sweating & $76.00(5.1)$ & $92.00(5.37)$ & 0.00 \\
\hline Sound & $80.00(6.66)$ & $80.00(6.66)$ & 1.00 \\
\hline Skin irritation & $90.00(0.00)$ & $75.00(7.45)$ & 0.00 \\
\hline Smell & $78.00(8.11)$ & $75.00(8.81)$ & 0.64 \\
\hline Wound & $92.00(8.10)$ & $85.00(9.42)$ & 0.08 \\
\hline Pain & $99.00(2.10)$ & $70.00(5.77)$ & 0.00 \\
\hline Frustration & $90.00(3.33)$ & $71.00(6.14)$ & 0.00 \\
\hline Swelling & $88.00(2.60)$ & $85.00(4.71)$ & 0.13 \\
\hline
\end{tabular}

Satisfaction: 100 represented "completely satisfied" and 0 indicated "not satisfied at all."

Problem: 100 represented "not bothered at all" and 0 indicated "extremely bothered."

resp.), walking with prosthesis (89.00 versus 78.00; $P=0.00$, resp.), walking on uneven surfaces (74.00 versus $66.50 ; P=$ 0.00 , resp.), feeling with the prosthesis (92.00 versus 669.00 ; $P=0.00$, resp.), and suspension with the prosthesis $(88.50$ versus $74.50 ; P=0.00$, resp.). Appearance and weight of the prosthesis do not show any differences (see Table 4). Overall satisfaction was $25.16 \%$ higher with Dermo liner compared with Pelite liner. Higher score was obtained with Dermo liner compared with Pelite liner during residuum skin irritation (90.00 versus $75.00 ; P=0.00$, resp.), pain (90.00 versus 70.00 ; $P=0.00$, resp.), and frustration with the prosthesis $(90.00$ versus $71.00 ; P=0.00$, resp.). Sweating was significantly less with Pelite liner compared with Dermo liner (92.00 versus $76.00 ; P=0.00$, resp.). Sound, smell, and wound between the two liners were not statistically significant (see Table 4).

3.3. Comparison between Seal-In X5 and Pelite Liner. Participants were significantly satisfied with Pelite liner compared with Seal-In X5 liner during donning/doffing (59.00 versus 87.00; $P=0.00$, resp.), walking (57.00 versus 78.00; $P=0.00$, resp.), walking on uneven surfaces (55.00 versus $66.50 ; P=$ 0.00 , resp.), and feeling with the prosthesis (55.00 versus 69.00; $P=0.00$, resp.). Suspension was significantly better with Seal-In X5 liner (see Table 5). In problems part between the two liners, significantly less sweating (92.00 versus 67.00 ; $P=0.00$, resp.) was recorded with Pelite liner and less pain (80.00 versus $70.00 ; P=0.00$, resp.) was observed with SealIn X5 liner. No differences were observed in smell, wound, and swelling with the two liners (see Table 5).

\section{Discussion}

Proper fitting of socket has significant effect on patient's satisfaction, comfort, and mobility [31]. We found significant differences between the three liners both in satisfaction and perceived problems. Participant demonstrated more satisfaction and fewer problems with Dermo liner compared with Pelite and Seal-In X5 liner.

In this study, the participants favored the Dermo liner with shuttle lock over the Pelite liner and Seal-In X5 liner. These findings reflect the previous study results [27], where clear preference was given for locking liners, while in other studies Coleman et al. and Boonstra et al. showed Pelite liner to be more favorable $[17,32]$. These studies oppose the findings of our research and were considerably less positive towards locking liners. The current study also mirrors the study of Ali et al. with regard to Dermo and Seal-In X5 liner [2].

Lower limb prosthesis should be functional and comfortable for the user, to give the best prospect of continued use [33]. In the study of Hatfield and Morrison [28] the participants felt more comfortable with the locking liners. Another study revealed that locking liners improved socket comfort when compared with Pelite liner [6]. In previous study the researchers also revealed that participants were more comfortable during walking and stairs negotiations with locking liners $[29,34]$. The same was true with our study as the participants showed more satisfaction during walking, walking on stairs, and walking on uneven ground with the locking liner. 
Table 5: Comparison between Seal-In X5 and Pelite liner.

\begin{tabular}{|c|c|c|c|}
\hline Variable & Seal-In X5 & Pelite & $P$ value \\
\hline & \multicolumn{3}{|c|}{ Satisfaction } \\
\hline Fit of prosthesis & $78.00(2.73)$ & $74.00(4.10)$ & 0.02 \\
\hline Donning/doffing & $59.00(12.41)$ & $87.00(8.12)$ & 0.00 \\
\hline Sitting with prosthesis & $87.00(4.27)$ & $83.00(6.32)$ & 0.14 \\
\hline Walking with prosthesis & $57.00(12.70)$ & $78.00(5.37)$ & 0.00 \\
\hline Walking on uneven surface & $55.00(8.35)$ & $66.50(4.74)$ & 0.00 \\
\hline Walking on stairs & $62.00(7.17)$ & $62.50(5.40)$ & 0.93 \\
\hline Appearance of prosthesis & $87.00(2.73)$ & $85.00(4.71)$ & 0.33 \\
\hline Feeling with prosthesis & $55.00(11.24)$ & $69.00(7.10)$ & 0.00 \\
\hline Weight of prosthesis & $86.00(5.47)$ & $86.00(5.16)$ & 1.00 \\
\hline Suspension & $91.00(7.37)$ & $74.50(11.41)$ & 0.00 \\
\hline \multirow[t]{2}{*}{ Overall satisfaction } & $63.00(7.91)$ & $66.00(11.25)$ & 0.53 \\
\hline & \multicolumn{3}{|c|}{ Problem } \\
\hline Sweating & $67.00(2.58)$ & $92.00(5.37)$ & 0.00 \\
\hline Sound & $82.00(8.10)$ & $80.00(6.66)$ & 0.51 \\
\hline Skin irritation & $83.00(5.41)$ & $75.00(7.45)$ & 0.02 \\
\hline Smell & $78.00(7.91)$ & $75.00(8.81)$ & 0.34 \\
\hline Wound & $90.00(9.42)$ & $85.00(9.42)$ & 0.20 \\
\hline Pain & $80.00(3.33)$ & $70.00(5.77)$ & 0.00 \\
\hline Frustration & $71.00(7.10)$ & $71.00(6.14)$ & 0.87 \\
\hline Swelling & $88.00(4.21)$ & $85.00(4.71)$ & 0.11 \\
\hline
\end{tabular}

Satisfaction: 100 represented "completely satisfied" and 0 indicated "not satisfied at all."

Problem: 100 represented "not bothered at all" and 0 indicated "extremely bothered."

Skin problems are often experienced with the prostheses use in transtibial amputees and appear in the form of skin irritation, ulcers, and abrasion $[35,36]$. These skin problems lead to discomfort and pain and in some cases amputees stop using the prosthesis for a period of time completely. This situation can impact satisfaction level of the amputees with prosthesis and badly affects on his/her mental health [37]. In the current research, less irritation and pain were experienced with the Dermo liner with shuttle lock compared to other liners, which mirror the studies of previous researchers [2, 29]. However, more sweating was experienced with the Dermo and Seal-In X5 liner compared with Pelite liner in our study which reflects the study of Hachisuka et al., where less sweating was reported with Pelite liner [38]. Participants feel more satisfied and experienced less pain with the Dermo liner, which leads them to walk more without any difficulties.

Fitting of socket and suspension system of prosthesis have great impacts on the participant's comfort, satisfaction, and mobility. Silicon liners are rolled over the residuum and closely attached to the skin of the residuum which creates a bond between the residuum and the liner. These qualities of the silicon liners have a positive outcome on suspension of the prosthesis $[19,20]$. Two research teams revealed improved suspension with the silicon liners in their research $[34,39]$. In another study researchers observed improvement in silicon liner suspension in $63 \%$ of participants compared to Pelite liner [38]. These studies mirror our results, where participants were more satisfied with Seal-In X5 and Dermo liner suspension. Many researchers recorded increase in the appearance of the prosthesis with the silicon liners which contradict the results of current study $[29,38]$. In the present research participant showed the same interest in the appearance of all the three types of prostheses.

Easy donning and doffing of the prosthesis has important effect on the prosthetic users. Significant easy donning and doffing $(P<0.00)$ has revealed with the Dermo liner compared with Pelite and Seal-In X5 liner in the current study. This is same with the previous study, where the research team revealed favor donning and doffing with the locking liners [34], while in another study the researchers found both decrease and improvement [29]. The entire participants reported significant difficulties in donning and doffing with Seal-In X5 liner in this research, which might be concluded that it is due to the five seals around the liner. These results reflect the study of Ali et al., where Dermo liner showed high score for donning and doffing compared with Seal-In X5 liner.

To compare our present study results with the existing literature, it was a challenge for us as there is no study available to compare the satisfaction and perceived problems between these three liners, especially between Seal-In X5 and Pelite liner. In summary all the participants feel satisfied with the Dermo liner and revealed high performance during level walking, stairs, and uneven surfaces. The results also clarify that the participants experienced less problems and frustration with the Dermo liner.

\section{Conclusion}

The present study demonstrated that the prosthetic liners influence the level of satisfaction of transtibial users. The 
study results showed that Dermo liner might be the best choice for transtibial users and these results might help the clinicians and prosthetic practitioners in selection criteria of prosthetic liners. However, further study is needed with larger sample size and more detail questionnaire to comprehensively compare the effect of these three liners on amputee's satisfaction and perceived problems.

\section{Conflict of Interests}

The authors declare that there is no conflict of interests regarding the publication of this paper.

\section{Acknowledgment}

This study was supported by University of Malaya/Ministry of Higher Education, Malaysia (UM/MOHE/HIR Project no. D000014-16001).

\section{References}

[1] X. Jia, M. Zhang, and W. C. C. Lee, "Load transfer mechanics between trans-tibial prosthetic socket and residual limb Dynamic effects," Journal of Biomechanics, vol. 37, no. 9, pp. 1371-1377, 2004.

[2] S. Ali, N. A. A. Osman, N. Mortaza, A. Eshraghi, H. Gholizadeh, and W. A. W. Wan Abas, "Clinical investigation of the interface pressure in the trans-tibial socket with Dermo and Seal-In X5 liner during walking and their effect on patient satisfaction," Clinical Biomechanics, vol. 27, no. 9, pp. 943-948, 2012.

[3] J. C. H. Goh, P. V. S. Lee, and Y. C. Sook, "Comparative study between patellar-tendon-bearing and pressure cast prosthetic sockets," Journal of Rehabilitation Research and Development, vol. 41, no. 3B, pp. 491-501, 2004.

[4] M. Zhang and C. Roberts, "Comparison of computational analysis with clinical measurement of stresses on below-knee residual limb in a prosthetic socket," Medical Engineering and Physics, vol. 22, no. 9, pp. 607-612, 2000.

[5] J. E. Sanders, J. M. Greve, C. Clinton, and B. J. Hafner, "Clinical study: changes in interface pressure and stump shape over time: preliminary results from a trans-tibial amputee subject," Prosthetics and Orthotics International, vol. 24, no. 2, pp. 163-168, 2000.

[6] I. Åström and A. Stenström, "Effect on gait and socket comfort in unilateral trans-tibial amputees after exchange to a polyurethane concept," Prosthetics and Orthotics International, vol. 28, no. 1, pp. 28-36, 2004.

[7] J. E. Sanders, S. G. Zachariah, A. B. Baker, J. M. Greve, and C. Clinton, "Effects of changes in cadence, prosthetic componentry, and time on interface pressures and shear stresses of three trans-tibial amputees," Clinical Biomechanics, vol. 15, no. 9, pp. 684-694, 2000.

[8] A. F. T. Mak, M. Zhang, and E. W. C. Tam, "Biomechanics of pressure ulcer in body tissues interacting with external forces during locomotion," in Annual Review of Biomedical Engineering, M. L. Yarmush, J. S. Duncan, and M. L. Gray, Eds., vol. 12, pp. 29-53, 2010.

[9] M. J. Hall, D. G. Shurr, M. J. Vanbeek, and M. B. Zimmerman, "The prevalence of dermatological problems for transtibial amputees using a roll-on liner," Journal of Prosthetics and Orthotics, vol. 20, no. 4, pp. 134-139, 2008.
[10] P. Lee, J. Goh, and S. Cheung, "Biomechanical evaluation of the pressure cast (PCast) prosthetic socket for transtibial amputee," in Proceedings of the World Congress on Medical Physics \& Biomedical Engineering, Chicago, Ill, USA, 2002.

[11] M. Zhang, A. R. Turner-Smith, A. Tanner, and V. C. Roberts, "Clinical investigation of the pressure and shear stress on the trans-tibial stump with a prosthesis," Medical Engineering \& Physics, vol. 20, no. 3, pp. 188-198, 1998.

[12] P. Dou, X. Jia, S. Suo, R. Wang, and M. Zhang, "Pressure distribution at the stump/socket interface in transtibial amputees during walking on stairs, slope and non-flat road," Clinical Biomechanics, vol. 21, no. 10, pp. 1067-1073, 2006.

[13] C. C. Lin, C. H. Chang, C. L. Wu, K. C. Chung, and I. Liao, "Effects of liner stiffness for trans-tibial prosthesis: a finite element contact model," Medical Engineering and Physics, vol. 26, no. 1, pp. 1-9, 2004.

[14] T. Bertels and T. Kettwig, "Breathable liner for transradial prostheses," in Proceedings of the Myoelectric Symposium, 2011.

[15] E. Boutwell, R. Stine, A. Hansen, K. Tucker, and S. Gard, "Effect of prosthetic gel liner thickness on gait biomechanics and pressure distribution within the transtibial socket," Journal of Rehabilitation Research and Development, vol. 49, no. 2, pp. 227240, 2012.

[16] F. B. van de Weg and D. van der Windt, "A questionnaire survey of the effect of different interface types on patient satisfaction and perceived problems among trans-tibial amputees," Prosthetics and Orthotics International, vol. 29, no. 3, pp. 231-239, 2005.

[17] K. L. Coleman, D. A. Boone, L. S. Laing, D. E. Mathews, and D. G. Smith, "Quantification of prosthetic outcomes: elastomeric gel liner with locking pin suspension versus polyethylene foam liner with neoprene sleeve suspension," Journal of Rehabilitation Research and Development, vol. 41, no. 4, pp. 591-602, 2004.

[18] S. Ali, N. A. Abu Osman, A. Eshraghi, H. Gholizadeh, N. A. Abd Razak, and W. A. Wan Abas, "Interface pressure in transtibial socket during ascent and descent on stairs and its effect on patient satisfaction," Clinical Biomechanics, vol. 28, no. 9, pp. 994-999, 2013.

[19] E. C. T. Baars and J. H. B. Geertzen, "Literature review of the possible advantages of silicon liner socket use in trans-tibial prostheses," Prosthetics and Orthotics International, vol. 29, no. 1, pp. 27-37, 2005.

[20] P. Gallagher and M. MacLachlan, "Development and psychometric evaluation of the trinity amputation and prosthesis experience scales (TAPES)," Rehabilitation Psychology, vol. 45, no. 2, pp. 130-154, 2000.

[21] A. W. Heinemann, R. K. Bode, and C. O’Reilly, "Development and measurement properties of the Orthotics and Prosthetics User's Survey (OPUS): a comprehensive set of clinical outcome instruments," Prosthetics and Orthotics International, vol. 27, no. 3, pp. 191-206, 2003.

[22] M. W. Legro, G. D. Reiber, D. G. Smith, M. Del Aguila, J. Larsen, and D. Boone, "Prosthesis evaluation questionnaire for persons with lower limb amputations: assessing prosthesis-related quality of life," Archives of Physical Medicine and Rehabilitation, vol. 79, no. 8, pp. 931-938, 1998.

[23] M. C. L. Grisé, C. Gauthier-Gagnon, and G. G. Martineau, "Prosthetic profile of people with lower extremity amputation: conception and design of a follow-up questionnaire," Archives of Physical Medicine and Rehabilitation, vol. 74, no. 8, pp. 862870, 1993.

[24] C. Gauthier-Gagnon and M.-C. Grise, "Prosthetic profile of the amputee questionnaire: validity and reliability," Archives of 
Physical Medicine and Rehabilitation, vol. 75, no. 12, pp. 13091314, 1994.

[25] G. M. Berke, J. Fergason, J. R. Milani et al., "Comparison of satisfaction with current prosthetic care in veterans and servicemembers from vietnam and OIF/OEF conflicts with major traumatic limb loss," Journal of Rehabilitation Research and Development, vol. 47, no. 4, pp. 361-372, 2010.

[26] H. Van der Linde, C. J. Hofstad, J. H. B. Geertzen, K. Postema, and J. Van Limbeek, "From satisfaction to expectation: the patient's perspective in lower limb prosthetic care," Disability and Rehabilitation, vol. 29, no. 13, pp. 1049-1055, 2007.

[27] I. McCurdie, R. Hanspal, and R. Nieveen, "ICEROSS-a consensus view: a questionnaire survey of the use of ICEROSS in the United Kingdom," Prosthetics and Orthotics International, vol. 21, no. 2, pp. 124-128, 1997.

[28] A. G. Hatfield and J. D. Morrison, "Polyurethane gel liner usage in the Oxford prosthetic service," Prosthetics and Orthotics International, vol. 25, no. 1, pp. 41-46, 2001.

[29] D. Datta, S. K. Vaidya, J. Howitt, and L. Gopalan, "Outcome of fitting an ICEROSS prosthesis: Views of trans-tibial amputees," Prosthetics and Orthotics International, vol. 20, no. 2, pp. 111-115, 1996.

[30] B. J. Hafner and D. G. Smith, "Differences in function and safety between Medicare Functional Classification Level-2 and -3 transfemoral amputees and influence of prosthetic knee joint control," Journal of Rehabilitation Research and Development, vol. 46, no. 3, pp. 417-433, 2009.

[31] S. Ali, N. A. Abu Osman, M. M. Naqshbandi, A. Eshraghi, M. Kamyab, and H. Gholizadeh, "Qualitative study of prosthetic suspension systems on transtibial amputees' satisfaction and perceived problems with their prosthetic devices," Archives of Physical Medicine and Rehabilitation, vol. 93, no. 11, pp. 19191923, 2012.

[32] A. M. Boonstra, W. van Duin, and W. Eisma, "Silicone Suction Socket (3S) versus supracondylar PTB prosthesis with pelite liner: Transtibial amputees'preferences," JPO: Journal of Prosthetics and Orthotics, vol. 8, no. 3, pp. 96-99, 1996.

[33] T. Dumbleton, A. W. P. Buis, A. McFadyen et al., "Dynamic interface pressure distributions of two transtibial prosthetic socket concepts," Journal of Rehabilitation Research and Development, vol. 46, no. 3, pp. 405-416, 2009.

[34] K. Yiǧiter, G. Şener, and K. Bayar, "Comparison of the effects of patellar tendon bearing and total surface bearing sockets on prosthetic fitting and rehabilitation," Prosthetics and Orthotics International, vol. 26, no. 3, pp. 206-212, 2002.

[35] S. Laing, P. V. Lee, and J. C. Goh, "Engineering a trans-tibial prosthetic socket for the lower limb amputee," Annals of the Academy of Medicine Singapore, vol. 40, no. 5, pp. 252-259, 2011.

[36] N. L. Dudek, M. B. Marks, S. C. Marshall, and J. P. Chardon, "Dermatologic conditions associated with use of a lowerextremity prosthesis," Archives of Physical Medicine and Rehabilitation, vol. 86, no. 4, pp. 659-663, 2005.

[37] H. E. J. Meulenbelt, P. U. Dijkstra, M. F. Jonkman, and J. H. B. Geertzen, "Skin problems in lower limb amputees: a systematic review," Disability and Rehabilitation, vol. 28, no. 10, pp. 603608, 2006.

[38] K. Hachisuka, K. Dozono, H. Ogata, S. Ohmine, H. Shitama, and K. Shinkoda, "Total surface bearing below-knee prosthesis: advantages, disadvantages, and clinical implications," Archives of Physical Medicine and Rehabilitation, vol. 79, no. 7, pp. 783789, 1998.
[39] J. Cluitmans, M. Geboers, J. Deckers, and F. Rings, "Experiences with respect to the ICEROSS system for trans-tibial prostheses," Prosthetics and Orthotics International, vol. 18, no. 2, pp. 78-83, 1994. 


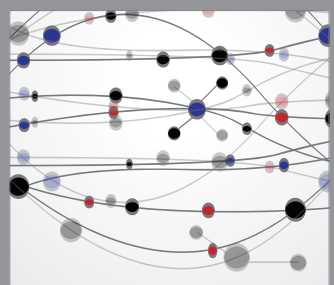

The Scientific World Journal
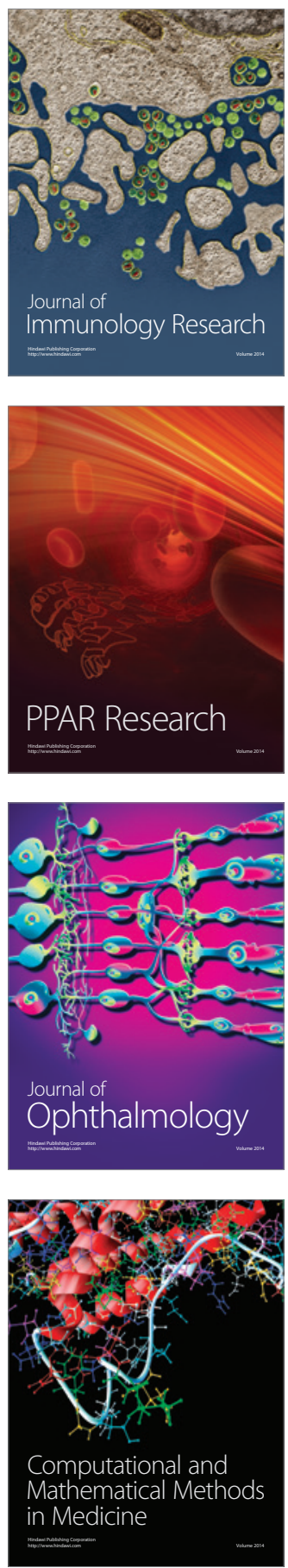

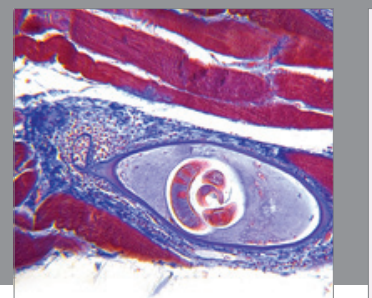

Gastroenterology

Research and Practice
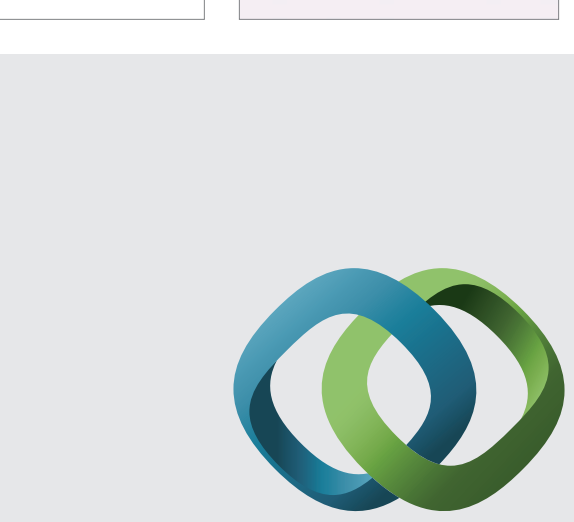

\section{Hindawi}

Submit your manuscripts at

http://www.hindawi.com
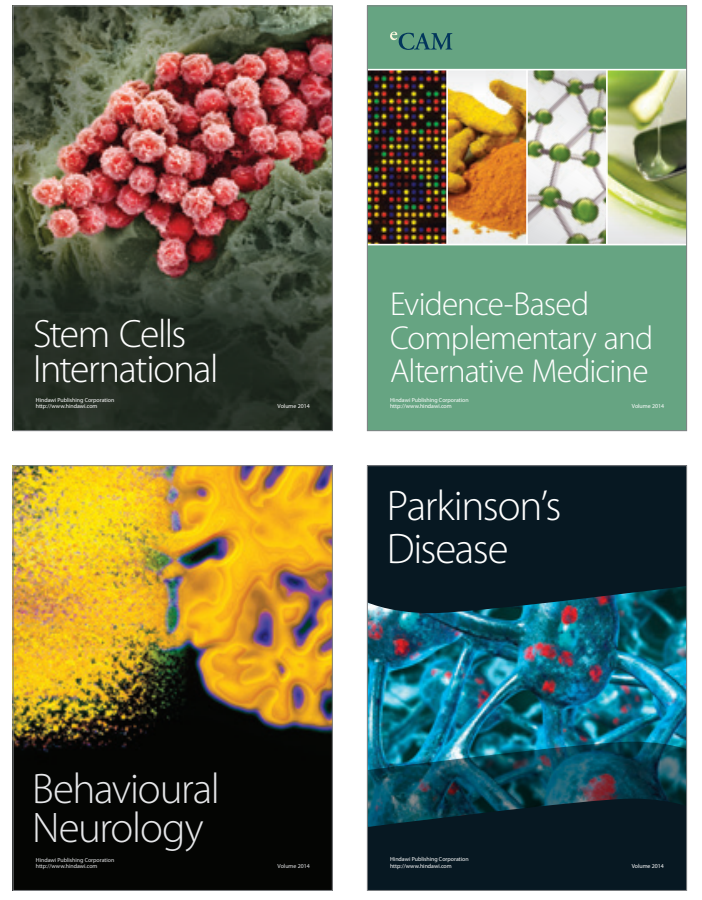
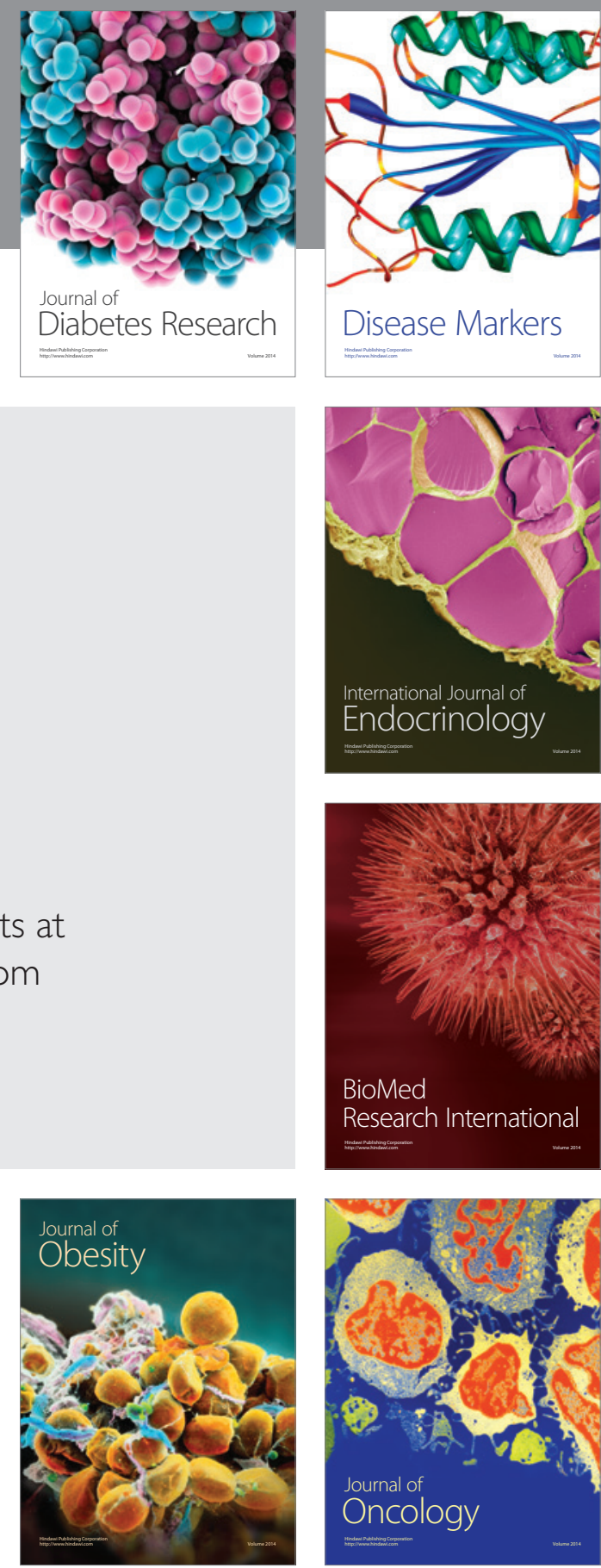

Disease Markers
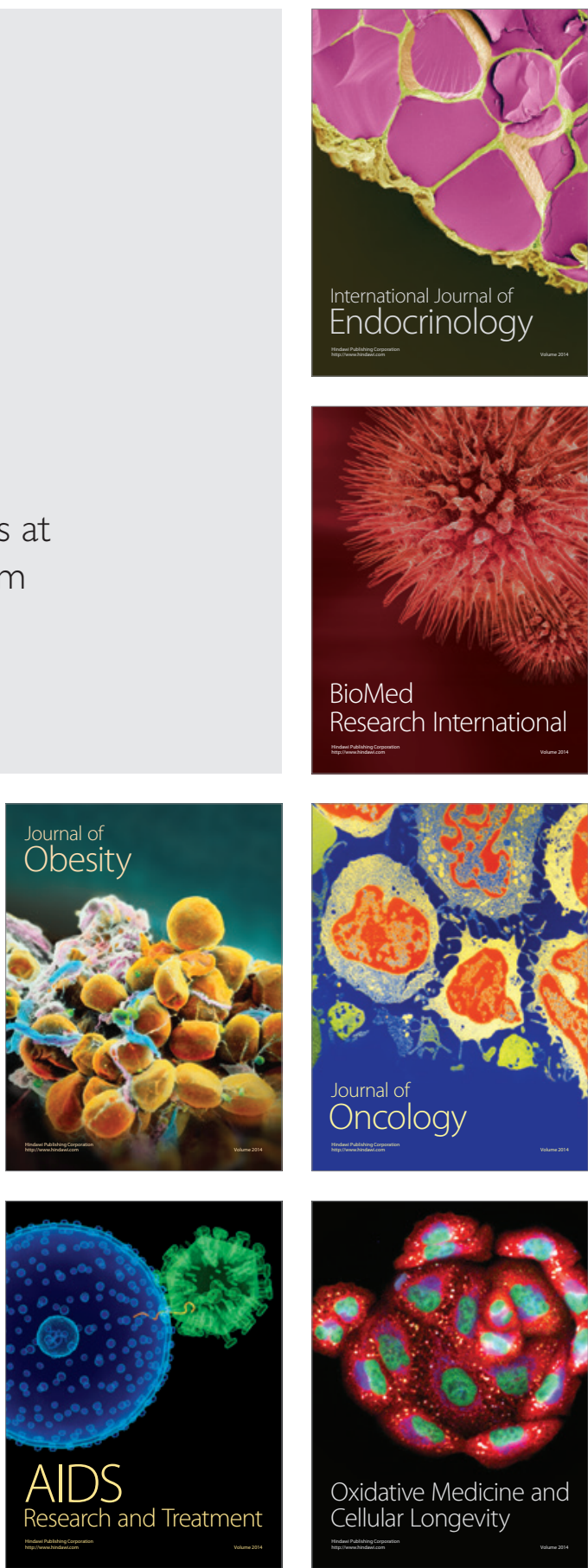